\title{
The Effect of Grandparents' Co-parenting on Young Children's Personality and Adaptation: Chinese Three-generation-families
}

\author{
Yi Sun ${ }^{1} \&$ Na Jiang ${ }^{2}$ \\ ${ }^{1}$ Ritsumeikan University, Japan \\ ${ }^{2}$ Keio University, Japan \\ Correspondence: Yi Sun, Global Innovation Research Organization, Ritsumeikan University, 2-150 Iwakura-cho, \\ Ibaraki, Osaka, 567-8570, Japan. E-mail: sysy_119@hotmail.com
}

Received: February 28, 2017

Accepted: March 13, 2017

Online Published: April 19, 2017

doi:10.5539/ass.v13n5p7

URL: https://doi.org/10.5539/ass.v13n5p7

\begin{abstract}
Due to the prevalence of grandparents' co-parenting of children in China, this study aimed to examine its influence on young children's personality and adaptation. With the cooperation of a kindergarten in Shanghai, 530 parents of children 3-6 years of age were invited to answer the questionnaire after giving their consent, and 422 of the questionnaires were effective. Three factors were extracted by Exploratory Factor Analysis for children's temperament: Fearfulness in Strange Situations (FS), Intensity of Reaction (IR) and Pro-social Activity (PA). Two factors were examined for children's adaptation: Separation Anxiety in attending kindergarten (SA) and Anxious Preoccupied Attachment (APA, one of the insecure types for parent-child attachment relationship). The results show that the children raised by only parents had higher PA than those co-raised by grandparents and lower APA than those raised by only grandparents. Even after controlling for the influence from temperament and grades, the effect of parenting styles on APA was still significant. For Grade 1 children, the parenting style was also significantly related to children's temperament (IR).
\end{abstract}

Keywords: grandparents, attachment, co-parenting, personality, adaptation

\section{Introduction}

\subsection{Prevalence of Grandparents ' Co-parenting}

Because of parental problems, such as parental substance abuse, incarceration, mental health problems, divorce, abandonment, economic difficulties, or maltreatment, the number of children who live in custodial grandparent families is growing (Hayslip \& Kaminski, 2005). In the U.S., grandparent-headed households increased 30\% from 1990 to 2000, and parents are entirely absent in many of these households (Simmons \& Dye, 2000). Researchers have taken an interest in the wellbeing of the children and their grandparents in such special situations (Poehlmann, Park, Bouffiou, Abrahams, Shlafer, \& Hahn, 2008; Ross \& Aday, 2006). However, few studies have addressed the wellbeing or development of young children who live in normal families but are raised or co-parented by their grandparents. Grandparents are taking on important co-parental responsibilities in contemporary China (Xiao, 2014; Li, 2013). In China, due to dual-career couples in most nuclear families (Tao, 2011) and the insufficient number of nurseries for young children under three years of age, grandparents have become the major caregivers of young children before these children go to school. In Shanghai (the second biggest city in China), more than $60 \%$ of families rely on grandparents to co-parent their children (Wang \& Cheng, 2014) during the day time while parents are working, after maternal childcare leave (usually four months after childbirth, according to Chinese Labor Law) or even from the first day of birth. Given that this is a becoming a prevalent social phenomenon, more research regarding the influence of grandparents' parenting/co-parenting in normal three-generational families is necessary.

\subsection{Grandparents' Parenting and Children's Development}

Regarding grandparenting, most research focuses on psychological and health problems in grandparents who provide primary care for their grandchildren (Minkler, Fuller-Thomson, Miller, \& Driver, 1997; Ross \& Aday, 2006; Poehlmann et al., 2008) or the factors of their well-being, such as their social economic status (Bachman \& Chase-Lansdale, 2005), their relationship with children's parents, family cohesion (Sands \& Goldberg-Glen, 2000) and grandchildren's behavior problems (Hayslip, Blumenthal, \& Garner, 2014). However, few studies have addressed the quality of grandparents' parenting or the effect of their parenting on children's development, 
though these are crucial areas for determining appropriate interventions to facilitate children's development and well-being (Poehlmann, 2003; Zhao, Deng, Zheng, \& Zhou, 2004). Grandparents may be the best substitute caregiver when parents are unavailable to provide care for their children, but the advantages and disadvantages in grandparenting for children's development should also be clarified to determine how to improve the quality of care and benefit the children's development.

\subsection{Child-parents Attachment}

From an attachment perspective, Poehlmann (2003) proposed that three relationship processes simultaneously occur when grandparents take responsibility for their grandchildren: (1) disruptions in attachments potentially occur, especially in relationships involving parents; (2) attachment relationships between grandchildren and grandparents develop or are revised; and (3) family members' internal working models of attachment and caregiving are challenged and shaped. However, little research has provided empirical evidence for Poehlmann's theory. Attachment relationship to caregivers (especially parents) is an important factor in children's development, which may influence children's internal working models (Bowlby, 1982) and have implication for their later social and emotional development (Bohlin, Hagekull, \& Rydell, 2000; Thompson, 1999). It is necessary to examine Poehumann's theory that grandparents' co-parenting will disrupt children's attachment to their parents in a normal three-generational family as well as in an atypical family with long absence of parents. Bowlby (1973) found that prolonged separation from parents will disrupt the attachment relationship between children and their parents. Although those children co-raised by their grandparents in normal three-generational families in China have no long term separation from their parents, the adverse factors such as the grandparents' presence as the primary caregivers, absence of parents in day time (when they are working), and various conflicts between parents and grandparents in parenting value may still exist for child-parent attachment,. Li, et al. (2015) reported that $83.74 \%$ of grandparents studied had been critical of children's mothers even before the grandchildren, and $30.54 \%$ had conflicts with children's mothers on parenting problems.

\subsection{Children's Social Adaptation}

However, Poehlmann's theory (2003) and related literature about children's attachment to their grandparents (Myers, Jarvis \& Creasey, 1987; Howes, 1999; Li, 2013) show that most grandparents raising grandchildren meet the criteria proposed to identify attachment figures because they provide consistent physical and emotional care for the children. Cui \& Lin (2015) even reported that children with grandparents as the primary caregivers scored significantly higher than those with parents as the primary caregivers in an attachment relationship survey because grandparents have more child-caring experience and respond to child's needs more sensitively and more patiently. Thus, for those children co-raised by their parents and grandparents, whether their primary caregivers are parents or grandparents or both, it is assumed that they at least have one stable attachment figure. Although understanding who will be the main attachment figure in such situation is also an interesting research question, this study focuses on whether the attachment relationship developed in this type of co-parenting style will function well in children's social adaptation. In well-developed attachment relationships, the caregiver presents a secure base from which a child can confidently explore their environment (Benoit, 2000). Will the children co-raised by grandparents adapt to a new environment as well as or even better than those raised only by parents? We compared the reaction of children raised by parents to those co-raised by grandparents in a real separation situation, i.e., attending kindergarten in a new semester, which is especially a challenging environment for new kindergarteners (Grade 1 children). The research on children's separation anxiety suggests that high-quality caring by grandparents had a compensatory effect for inadequate care by parents (Wang, Liu \& Wang, 2011) and that a good attachment relationship with grandparents could relieve children's anxiety ( $\mathrm{Li}, 2013)$. Thus, it is supposed that there is no difference between children raised by parents and those who are co-raised by grandparents when separating from the caregiver(s) to attend kindergarten.

\subsection{Children's Temperament}

This study also examined whether grandparents' co-parenting influences children's behavioral characteristics. Compared with the children raised by young parents, those raised by grandparents tend to be involved in less social or outdoor activities due to the grandparents' physical weakness (Poehlmann et al., 2008; Li, 2013) and comparatively low social economic status (Fuller-Thompson, Minkler, \& Driver, 1997). Thus, it is assumed that grandparents' co-parenting will influence children's pro-social behavior or reaction in strange situations. Children's fearfulness for strangers and strange situations may also result from insecure attachment relationships with their parents (Zhou \& Xu, 2012; Ispa, Fine, \& Thornburg, 2002). Moreover, grandparents tend to dote on and even spoil their grandchildren, which may characterize children as more self-centered, and the children may exhibit a more intensive reaction in frustrating situations (Wang, 2007). 


\subsection{Hypothesis}

Regarding children's personality and adaptation in a three-generation-family with grandparents as primary caregiver of children, the hypotheses in this study were as follows:

a) Parent-child attachment: grandparents' co-parenting will disrupt the attachments between children and their parents;

b) Social adaptation: children co-raised by grandparents will adjust to kindergarten as well as those raised by parents;

c) Children's temperament: children co-raised by grandparents show more negative disposition (higher fearfulness in strange situation and more intensive reaction in frustrating situations).

According to the above, the hypothesis model for the relationships between grandparents' parenting and the other variables was assembled in Figure 1. It is assumed that Grandparents' parenting will directly affect children's temperament and their attachment relationship to parents, and will indirectly influence children's social adaptation via temperament and parent-child attachment.

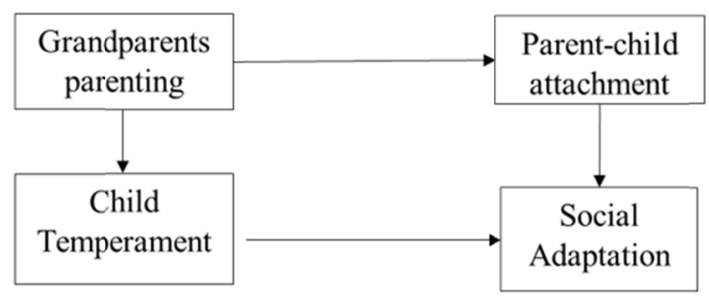

Figure 1. The hypothesis model for ralationship of parenting style, temperament and adaptation

\section{Method}

\subsection{Participants and Procedures}

With the cooperation of a kindergarten in Shanghai, 530 parents of children 3-6 years of age were invited to participate in the investigation by their consent during the first month of attending kindergarten. Parents were asked to complete the questionnaire independently at home. The researchers collected the answers after one week, and 422 of the questionnaires were effective. Among the 422 children, 143 (33.9\%) were in 1st Grade, 141 (33.4\%) were in 2nd Grade, and 138 (32.7\%) were in 3rd Grade. In addition, 252 (59.7\%) of the children were boys, and 170 (40.3\%) were girls. The mean (SD) age of parents and grandparents is shown in Table 1.

Table 1. Age of parents and grandparents (years)

\begin{tabular}{cccc}
\hline & Mean & SD & Range \\
\hline Father & 32.98 & 3.64 & $23-55$ \\
Mother & 30.99 & 3.37 & $21-44$ \\
Paternal grandfather & 58.95 & 5.48 & $48-85$ \\
Paternal grandmother & 57.29 & 5.48 & $44-80$ \\
Maternal grandfather & 57.68 & 5.60 & $46-82$ \\
Maternal grandmother & 56.37 & 5.46 & $45-78$ \\
\hline
\end{tabular}

\subsection{Measurements}

Demographic variables included age/gender/received education of parents, length of maternity leave, age of grandparents, age/gender/grade of children, and parenting style (i.e., in daily life, child's care was provided by only-parents, parents and grandparents, or only-grandparents).

\subsection{Attachment between Children and Parents}

Five items that represent the anxious-preoccupied type were used to assess the adverse influence of grandparenting on parent-child attachment. These items were selected from the Attachment Questionnaire for Two- to Four-year-old Children, which was developed for Chinese children by Hong (2008) with good reliability and validity. In most Chinese three-generation-families, the children spend more time with their grandparents than with their parents; therefore, it is assumed that their attachment needs for parents are less satisfied. Thus, those children raised by grandparents might need more care and attention from their parents, and anxious-preoccupied attachment will occur more easily in Chinese children than other insecure types. 
The five items of Anxious/Preoccupied Attachment (APA) were modified according to the life situation with grandparents (for example, "When I am going to leave home and let the child stay with baby sitter or other care-giver such as grandparents, he/she will cry and blubber, and ask me to stay with him/her"; "When the child is playing at home, he/she always pays attention to me and often call me to check where I am"), and they are rated on a 5-point Likert interval response scale from 'Absolutely inappropriate' to 'Absolutely appropriate'. The higher score indicates a more insecure attachment to parents. Cronbach's $\alpha$ for the five items of APA was .60.

\subsection{Separation Anxiety in attending kindergarten}

Five items were used to assess children's Separation Anxiety (SA) in attending kindergarten (for example, "When the child arrives at the classroom, he/she will find a lot of excuse to let me not to leave from classroom"; "On every Monday morning, the child always cries or is sad, not want to go to kindergarten"). These items were developed for this study according to the Children's Anxiety Scale in Attending Kindergarten (Liu, Yu, Li, \& Xie, 2005). The items were rated on a 5-point Likert interval response scale from 'Absolutely inappropriate' to 'Absolutely appropriate'. The higher score suggests a worse adaptation in attending kindergarten. Cronbach's $\alpha$ for the five items was .82 .

\subsection{Children's temperament}

To assess children's reaction in strange and frustrating situations, we used two ('fearfulness for stranger and strange situation' and 'intensity of reaction') of the nine dimensions in the Toddler Temperament Scale (TTS, Fullard, McDevitt \& Carey, 1984). TTS is a parental questionnaire developed to identify temperament profiles for small children based on the New York Longitudinal Study (NYLS) findings. In NYLS, Thomas and Chess have identified nine temperament categories that describe the manner in which a child behaves: activity level, biological rhythmicity, initial approach/withdrawal, adaptability, intensity, mood, persistence/attention span, distractibility, and sensory threshold.

Referring to the Chinese version of the TTS (Hong, Zhang, Zhou, Yao, \& Liu, 1999) and the life situation of the typical Chinese three-generation-family, we selected 10 items to assess 'Fearfulness for stranger and strange situation' and 6 items to assess 'Intensity of reaction'. These items were rated on a 5-point Likert interval response scale from 'Absolutely inappropriate' to 'Absolutely appropriate'. However, for the 16 items from two dimensions of the TTS, we failed to extract two factors as expected using a confirmatory factor analysis. The three reverse items for 'Fearfulness for Stranger and strange situation' were extracted as another factor using Exploratory Factor Analysis. Thus, three factors were extracted in this study, and they were labeled 'Fearfulness for Stranger and strange situation' (FS, 6 items, for example "The child was very shy with strangers when he/she was a little boy/girl"), 'Pro-social Activity' (PA, 3 items, for example "The child is extroversive and likes to talk with others") and 'Intensity of Reaction' (IR, 6 items, for example "When the child fails to do something during playing, he/she always cries or screams intensely"). Cronbach's $\alpha$ s for the three variables were $.78, .74$ and .83 , respectively.

\section{Results}

\subsection{Descriptive Statistics}

Table 2 shows the frequency and percentage of length of maternity leave, received education of parents and parenting styles.

Table 2. Descriptive statistics of demographic variables

\begin{tabular}{|c|c|c|c|}
\hline & & $n$ & $\%$ \\
\hline \multirow{3}{*}{ maternity leave } & $<0.5$ years & 197 & 49.3 \\
\hline & $0.5 \sim 1$ years & 132 & 33.0 \\
\hline & $1 \sim 3$ years & 71 & 17.8 \\
\hline \multirow{4}{*}{ education of mothers } & middle school & 44 & 10.6 \\
\hline & high middle school & 108 & 25.9 \\
\hline & college/university & 262 & 62.8 \\
\hline & graduate school & 3 & 0.7 \\
\hline \multirow{4}{*}{ education of fathers } & middle school & 23 & 5.5 \\
\hline & high middle school & 117 & 27.9 \\
\hline & college/university & 263 & 62.6 \\
\hline & graduate school & 17 & 4.0 \\
\hline \multirow{3}{*}{ parenting style } & only parents & 53 & 12.6 \\
\hline & parents \& grandparents & 260 & 61.6 \\
\hline & only grandparents & 109 & 25.8 \\
\hline
\end{tabular}




\subsection{Comparison of Temperament and Adaptation by Grades}

The temperament and adaptation of preschool children was compared by grades using the one-way analysis of variance (one-way ANOVA). The results show that there is significant difference among the three groups (Grade 1, Grade 2, and Grade 3) in Intensity of Reaction (IR), PA (Pro-social Activity), Anxious/Preoccupied Attachment (APA), and Separation Anxiety (SA), F $(2,419)=4.73, \mathrm{p}<.01 ; \mathrm{F}(2,419)=3.65, \mathrm{p}<.05 ; \mathrm{F}(2,419)$ $=7.88, \mathrm{p}<.001 ; \mathrm{F}(2,419)=14.93, \mathrm{p}<.001$, respectively; whereas, we found no significant difference in Fearfulness for Strange (FS), F $(2,419)=.814$, n.s. The result of multiple comparisons between groups is shown in Table 3. The result suggests that the Grade 1 children had higher IR, APA and SA but lower PA than the other two groups.

Table 3. Multiple comparisons of personality and adaptation between grades

\begin{tabular}{|c|c|c|c|c|c|}
\hline & Group & $n$ & Mean & & SD \\
\hline \multirow{3}{*}{ Fearfulness for Strange } & Grade1 & 143 & 20.04 & & 5.08 \\
\hline & Grade2 & 141 & 19.47 & & 4.95 \\
\hline & Grade3 & 138 & 19.32 & & 5.07 \\
\hline \multirow{3}{*}{ Intensity of Reaction } & Grade1 & 143 & 16.15 & $\mathrm{a}$ & 5.29 \\
\hline & Grade2 & 141 & 15.45 & & 5.95 \\
\hline & Grade3 & 138 & 14.15 & $\mathrm{~b}$ & 5.25 \\
\hline \multirow{3}{*}{ Pro-social Activity } & Grade1 & 143 & 8.87 & $\mathrm{a}$ & 3.32 \\
\hline & Grade2 & 141 & 9.82 & $\mathrm{~b}$ & 3.49 \\
\hline & Grade3 & 138 & 9.78 & & 3.21 \\
\hline \multirow{3}{*}{ Anxious Preoccupied Attachment } & Grade1 & 143 & 13.15 & $\mathrm{a}$ & 4.39 \\
\hline & Grade2 & 141 & 11.97 & $\mathrm{~b}$ & 4.20 \\
\hline & Grade3 & 138 & 11.19 & $\mathrm{~b}$ & 3.94 \\
\hline \multirow{3}{*}{ Separation Anxiety } & Grade1 & 143 & 8.30 & $\mathrm{a}$ & 4.31 \\
\hline & Grade2 & 141 & 6.60 & $\mathrm{~b}$ & 2.93 \\
\hline & Grade3 & 138 & 6.30 & $\mathrm{~b}$ & 2.38 \\
\hline
\end{tabular}

Note: there is significant difference between a and $\mathrm{b}, \quad p<.05$.

\subsection{Comparison of Temperament and Adaptation by Parenting Styles}

The results of the comparison of temperament and adaptation by parenting styles show that there is significant difference among the three groups (children raised only by parents, by parents and grandparents, and only by grandparents) in PA and APA, F $(2,419)=8.06, \mathrm{p}<.01 ; \mathrm{F}(2,419)=3.42, \mathrm{p}<.05$, respectively; however, we found no significant difference in FS, IR, and SA, F $(2,419)=.92 ; 1.90 ; .79$, n.s. The result of multiple comparisons between groups is shown in Table 4. It suggests that the children raised only by parents had higher PA than the other two groups and lower APA than those raised by only-grandparents.

Table 4. Multiple comparisons of personality and adaptation by parenting styles

\begin{tabular}{cccccc}
\hline & Group & $\boldsymbol{n}$ & Mean & SD \\
\hline \multirow{3}{*}{ Pro-social Activity } & only parents & 53 & 10.91 & $\mathrm{a}$ & 2.84 \\
& co-parenting & 260 & 9.52 & $\mathrm{~b}$ & 3.32 \\
& only-grandparents & 109 & 8.69 & $\mathrm{~b}$ & 3.48 \\
\hline \multirow{2}{*}{ Anxious Preoccupied } & only parents & 53 & 11.00 & $\mathrm{a}$ & 4.46 \\
Attachment & co-parenting & 260 & 12.05 & $\mathrm{~b}$ & 4.15 \\
& only-grandparents & 109 & 12.83 & $\mathrm{~b}$ & 4.30 \\
\hline
\end{tabular}

Note: there is significant difference between a and $\mathrm{b}, p<.05$.

\subsection{Relationship between Parenting Style, Temperament and Adaptation}

To examine the effect of parenting styles on children's attachment and separation anxiety more rigorously and holistically, the relationship between parenting styles and APA/SA was tested by path model while controlling for the influence from the other variables (children's temperament and their grades). The results show that grades were related to the temperament (IR) and adaptation (APA/SA) (consistent with the above results of Table 3), and the temperament (IR/FS) also had an influence on APA/SA. After controlling for these influences from 
children' $s$ temperament (IR/FS $\rightarrow$ APA/SA) and grades (Grade $\rightarrow$ IR/APA/SA), the effect of parenting style on APA was still significant (Figure 2). The model fitness is good. Because no significant relationship was found between PA and the outcome variable (parent-child attachment, social adaptation), PA was moved out from this model. The path from SA to APA was not significant, so it was deleted, and the model fitness showed better than before.

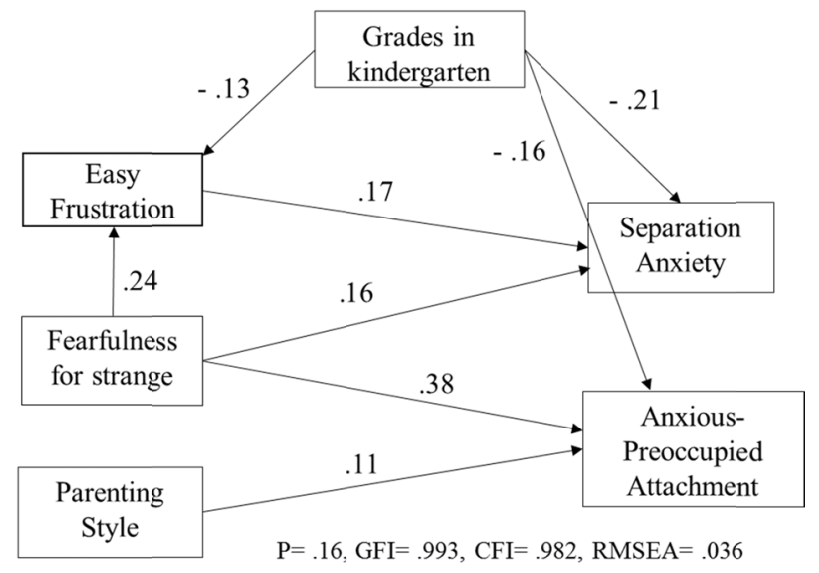

Parenting style: $1=$ only parents; 2 = co-parenting; 3 = only grandparents

Figure 2. The relationship between parenting style, temperament and adaptation (all)

Furthermore, the relationship model of Figure 2 was examined based on the children's grades. Interestingly, for the group of Grade 1 children, the parenting style was also significantly related to the children's temperament (i.e., IR) (Figure 3). However, no such relationship was found in the other two groups.

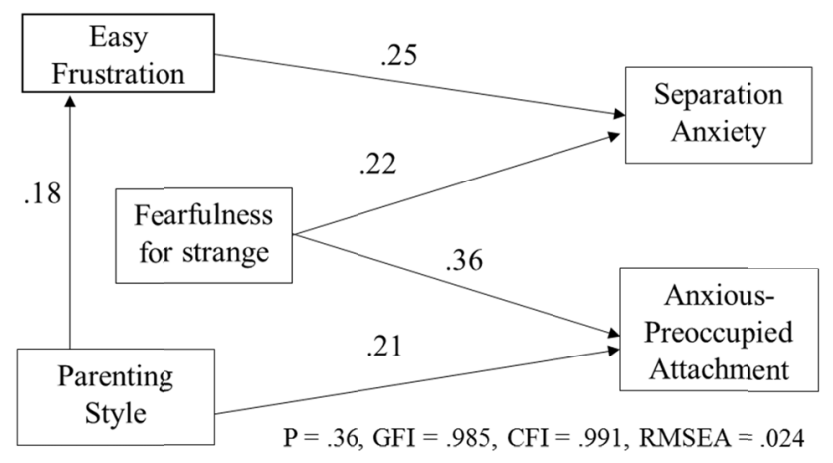

Parenting style: $1=$ only parents; 2 = co-parenting; $3=$ only grandparents

Figure 3. The ralationship between parenting style, temerament and adaptation (Grade 1 children)

\section{Discussion}

\subsection{Grandparents' Co-parenting in China}

Regarding the sample of this study, approximately $50 \%$ of mothers had short maternity leave (less than half year); thus, co-parenting with grandparents occurred in more than $60 \%$ of the families. The sample is thought to have good representativeness for parenting style in present Chinese families with young children in urban areas.

\subsection{Changes in children's personality and social adaptation with age and grade}

The comparison of temperament and adaptation by grades indicates that children's IR, APA and SA decreased, but PA increased with the increase of school ages. This result implies that as children psychologically mature and their social experience is increased in kindergarten with peers and other adults other than family members, their temperaments become milder with less intense reactions and more pro-social activities. Thus, we should consider and control the biological factors and the larger social environment factors, not only the family environment, when discussing the influence of family environment on children's personality. 


\subsection{The influence of grandparents' co-parenting on parent-child attachment}

The results indicate that the children raised by only-parents showed significant lower APA than those raised by only-grandparents. This finding implies that when grandparents act as the primary or only caregivers of children, the inadequate contact with parents might cause children to develop an insecure attachment (i.e. APA) relationship to their parents. It provides evidence for Poehlmann's theory (2003) that grandparenting will disrupt the attachment relationship between children and their parents. Although there is no significant difference in the score of APA between the co-parenting group and the other two groups, a tendency could still be detected. The more grandparents participate in parenting, the higher children's APA will be. After controlling for the influence of children's school age and temperament, the tendency was confirmed to be significant by path analysis (Figure 1). Whether the negative influence of grandparenting on parent-child attachment will continue until the children grow up and whether the disrupted parent-child attachment relationship will influence children's later social development is not known. Further investigations for older children or follow up studies are necessary.

\subsection{Parenting style and children's adaptation in attending kindergarten}

No significant difference was found in SA between the children co-raised by grandparents and those raised only by parents. This finding implies that parenting style has no direct influence on children's adaptation in attending kindergarten, and it supports the hypothesis of this study that children co-raised by grandparents will attend kindergarten as well as those raised by parents. This study is consistent with the previous research that for those double-working families, grandparents' compensatory care-giving is helpful for children to develop a secure attachment so that they can adapt to kindergarten life earlier (Li, 2013). Main, Kaplan \& Cassidy (1985) noted that children with secure attachment would adapt to a separation situation better.

Plehlmann (2003) argued that although children raised by grandparents because of parental problems are likely to have experienced disrupted attachments, there is the potential for resilience, especially within the context of nurturing and supportive extended family relationships. Most Chinese grandparents do their best to support their adult children to take care of their grandchildren, who might have experienced disrupted attachment or have never built good attachment with their parents. For these children, stable grandparents-grandchildren attachments are thought to provide a secure base for them to explore outside world.

\subsection{Grandparenting and children's temperament}

Although the only-parents-parenting families only occupied $12.6 \%$ in this sample, we found that children raised by only-parents showed higher pro-sociality than the other two groups (Table 4). The children raised by only-grandparents showed the lowest pro-sociality. Han, Wu \& Gao (2014) also reported that the children raised by grandparents showed lower social development. Perhaps grandparents provide less social communication or outdoor activities for young children due to their physical weakness and decreasing social participation. However, no significant correlation was found between the pro-sociality and children's adaptation (SA or APA). So the relationship about the three factors (parenting style, pro-sociality, adaptation) was not examined further in the multiple variables model (Figure 2). Perhaps as discussed above, the pro-sociality might improve with children's age and their social experience in kindergarten, so the relationship between pro-sociality and adaptation was not significant when combining all the children from Grade 1 to Grade 3. Another explanation is that pro-sociality does not influence SA or APA at all. Although the items of pro-sociality could be used as reversal items of FS like in the original TTS, it is thought necessary to divide the factor of pro-sociality from FS, since it has different relationship with the other variables.

FS was found strongly related to SA and APA but not related to parenting style. Perhaps FS is a temperament factor based more on biology and less influenced by environment.

Regarding IR, for the children of Grade 1, the results of the path analysis (Figure 3) indicate that parenting style had a significant effect on children's IR, i.e., the more grandparents took part in parenting, the more intensive reaction children showed in frustrating situations or when they fail to do something. This result in part supports the hypothesis of this study that children (co-)raised by grandparents show a more negative disposition. Perhaps this is because grandparents are more likely to spoil children by always gratifying children's needs and desires unconditionally. It may make children more self-centered, and when their needs are not satisfied, the children may express more negative affection than others, especially at home ( $\mathrm{Li}, 2013$; Wang, 2007). Meanwhile, children's IR is found to be related to their reaction and behavior in the separation situation when attending kindergarten (SA). This implies that parenting style might affect SA indirectly via IR, although it did not relate to SA directly. However, the relationship between parenting style and temperament (IR) was not found for Grade 2 and Grade 3 children. One explanation for this finding is that family members may greatly influence children's personality before three years old, but with the increase of their maturity and social experience (with peers or 
other adults other than family members) after entering kindergarten, the influence from family environment might weaken for children, as mentioned above.

\section{Acknowledgments}

We are grateful to Shanghai Baiyun Kindergarten to give great cooperation to our investigation.

\section{Compliance with Ethical Standards}

The authors declare no conflict of interest associated with this manuscript.

The participants voluntarily participated in the surveys, and the informed consent was obtained by filling out the questionnaire.

\section{References}

American Psychological Association. (1972). Ethical standards of psychologists. Washington, DC: American Psychological Association.

Bachman, H. J., \& Chase-Lansdale, P. L. (2005). Custodial grandmothers' physical, mental, and economic well-being: Comparisons of primary caregivers from low-income neighborhoods. Family Relations, 54, 475-487. https://doi.org/10.1111/j.1741-3729.2005.00334.x

Benoit, D. (2000). Attachment and parent-infant relationships: A review of attachment theory and research. Ontario Association of Children's Aid Societies Journal, 44(1), 13-23.

Bohlin, G., Hagekull, B., \& Rydell, A. M. (2000). Attachment and social functioning: A longitudinal study from infancy to middle childhood. Social Development, 9, 24-39. https://doi.org/10.1111/1467-9507.00109

Bowlby, J. (1973). Attachment and Loss: Vol. 2, Separation-Anxiety and Anger. New York: Basic Books.

Bowlby, J. (1982). Attachment and loss: Vol. 1, Attachment. New York: Basic Books.

Cui, X. \& Lin, Y. (2015). The impact of caregivers' identity on the development of preschoolers' attachment. Chinese Early Childhood Education, 667, 41-45.

Fullard, W., McDevitt, S. C., \& Carey, W. B. (1984). Assessing temperament in one-year-old to 3-year-old children. Journal of Pediatric Psychology, 9(2), 205-217. https://doi.org/10.1093/jpepsy/9.2.205

Fuller-Thompson, E., Minkler, M., \& Driver, D. (1997). A profile of grandparents raising grandchildren in the United States. The Gerontologist, 37(3), 406-411. https://doi.org/10.1093/geront/37.3.406

Han, P. G., Wu, Y. P., \& Gao, F. Q. (2014). The shyness and social development of the top class children in kindergarten. Chinese Journal of Child Health Care, 22(12), 1290-1292.

Hayslip B. Jr., \& Kaminski, P. L. (2005). Grandparents raising their grandchildren: A review of the literature and suggestions for practice. The Gerontologist, 45(2), 262-269. https://doi.org/10.1093/geront/45.2.262

Hayslip, B., Jr., Blumenthal, H., \& Garner, A. (2014). Health and grandparent-grandchild well-Being: One-year longitudinal findings for custodial grandfamilies. Journal of Aging and Health, 26(4), 559-582. https://doi.org/10.1177/0898264314525664

Hong, P. (2008). A compile of attachment questionnaire for two-to-four-year-old children and assessment of their attachment security. Zhejiang University, Hangzhou, China. dissertation, B844.1

Hong, Q., Zhang, F., Zhou, S. L., Yao, K. N., \& Liu, L. (1999). Standardization and revision of the children temperament scales. Chinese Journal of Pediatrics, 37(3), 135-138.

Howes, C. (1999). Attachment relationships in the context of multiple caregivers. In J. Cassidy \& P. R. Shaver (Eds.), Handbook of attachment: Theory, research, and clinical applications. New York: Guilford.

Ispa, J., Fine, M. A., \& Thornburg, K. R. (2002). Maternal personality as a moderator of relations between difficult infant temperament and attachment security in low income families. Infant Mental Health Journal, 23, 130-144. https://doi.org/10.1002/imhj.10008

Li, D., Wang, Z., Zhu, X., Wang, J., Pan, Y., \& Liang, A. (2015). Study on current situation of parentsgrandparents coparenting in families with infants in Beijing urban area. Maternal and Child Health Care of China, 30(9), 1397-1400.

Li, F. X. (2013). The influence of grandparent' child-caring on parent-child attachment relationship. Journal of Ningxia Teachers University, 34(4), 130-133.

Liu, H. J., Yu, C. J., Li, Y., \& Xie, X. X. (2005). Research on theory of mind and temperament type for young 
children with kindergarten enrollment anxiety. Chinese Journal of Child Health Care, 13(6), 496-498.

Main, M., Kaplan, N., Cassidy, J. (1985). Security of infancy childhood and adulthood: A move to the level of representation. In I. Bretherton, \& E. Waters (Eds.), Growing points of attachment theory and research. Monographs of the Society for Research in Child Development, 50, 66-106. https://doi.org/10.2307/3333827

Minkler, M., Fuller-Thomson, E., Miller, D., \& Driver, D. (1997). Depression in grandparents raising grandchildren: Results of a national longitudinal study. Archives of Family Medicine, 6(5), 445-452. https://doi.org/10.1001/archfami.6.5.445

Myers, B. J., Jarvis, P. A., \& Creasey, G. L. (1987). Infants' behavior with their mothers and grandmothers. Infant Behavior and Development, 10, 245-259. https://doi.org/10.1016/0163-6383(87)90015-4

Poehlmann, J. (2003). An attachment perspective on grandparents raising their very young grandchildren: Implications for intervention and research. Infant Mental Health Journal, 24, 149-173. https://doi.org/10.1002/imhj.10047

Poehlmann, J., Park, J., Bouffiou, L., Abrahams, J., Shlafer, R., \& Hahn, E. (2008). Representations of family relationships in children living with custodial grandparents. Attachment \& Human Development, 10, 165-188. https://doi.org/10.1080/14616730802113695

Ross, M. E. T., \& Aday, L. (2006). Stress and coping in African American grandparents who are raising their grandchildren. Journal of Family Issues, 27, 912-932. https://doi.org/10.1177/0192513X06287167

Sands, R. G., \& Goldberg-Glen, R. S. (2000). Factors associated with stress among grandparents raising their grandchildren. Family Relations, 49, 97-105. https://doi.org/10.1111/j.1741-3729.2000.00097.x

Simmons, T., \& Dye, J. L. (2000). Grandparents Living With Grandchildren: 2000. Census 2000 Brief. Issued October 2003.

Tao, Y. (2011). Intergenerational reciprocal care or welfare default? : Gender and intergenerational exchange of care in domestic labor in dual-earner families. Collection of Women's Studies, (4), 13-19.

Thompson, R. A. (1999). Early attachment and later development. In J. Cassidy \& P. R. Shaver (Eds.), Handbook of attachment: Theory, research, and clinical applications. New York: Guilford.

Wang, L. F. (2007). Investigation on the mental health of preschoolers raised by their grandparents. Chinese Mental Health Journal, 21(10), 672-674.

Wang, Z. Y. \& Cheng, N. H. (2014). Co-Parenting and the influence on child adjustment. Advances in Psychological Science, 22(6), 889-901. https://doi.org/10.3724/SP.J.1042.2014.00889

Xiao, S. (2014). "Yan Mu Ci Zu". The intergenerational collaboration and conflicts in childrearing among urban families in contemporary China. Sociological Studies, (6), 148-171.

Zhao, M., Deng, S. Y., Zheng, R. C., \& Zhou, X. (2004). From grandparent to surrogate parent: review of the grandparents' role in the Western. Chinese Psychological Development and Education, 20(4), 94-96.

Zhou, N. \& Xu, F. (2012). Analysis the influence of parenting absent on rural young children's social development. Studies in Early Childhood Education, 215, 26-30.

\section{Copyrights}

Copyright for this article is retained by the author(s), with first publication rights granted to the journal.

This is an open-access article distributed under the terms and conditions of the Creative Commons Attribution license (http://creativecommons.org/licenses/by/4.0/). 